\title{
Consonant Changes in Korean Singers' Pronunciation
}

\author{
Sendy Intania Hermastuti \& Arina Isti'anah \\ sendinher1535@gmail.com \& arina@usd.ac.id \\ English Letters Department, Universitas Sanata Dharma, Yogyakarta
}

\begin{abstract}
Music industry in Indonesia is now filled with many genres or types of music. One of them that is very famous nowadays is a music genre called K-pop or Korean pop, originating from South Korea. In line with the development of K-pop music that continues worldwide, Korean singers start making English songs. There were two objectives to be discussed in this article: to find out the consonants that are usually changed or replaced by Korean singers and find the phonological patterns found in the consonant changes. Phonological approach was conducted by involving purposive sampling technique to collect the data. Songs by Wonder Girls, Super Junior, Bigbang, and CN Blue were analyzed in terms of the consonant changes that occurred in Korean singers' pronunciation. The analysis showed that there were 7 English consonants that underwent changes in Korean singers' pronunciation. Fricatives are found as the consonants that usually undergo a change. Furthermore, the phonological processes that were usually found in those consonant changes were the process of changing fricatives into stops or affricate consonants, process of changing [r] into [l], and the last is the process of palatalization.
\end{abstract}

Keywords: consonant change, Korean, phonology.

\section{Introduction}

Language is a tool for communication in written or spoken words. It is used by the people of a particular country or area in order to communicate to each other. There are many languages spoken by human beings in this world. However, the language that is recognized as one of the most widely spoken language is English, which now becomes a language that is used internationally. Besides used as a native language in some countries, English is also used as a foreign language in many other countries. In the countries that regard English as a foreign language, the use of English by the non-native speakers of English serves "the purpose as a vehicle for science, for the mass media (press, radio, television), and some kinds of international entertainment" (Strevens, 1980: 62).

Talking about the use of English in some kinds of international entertainment, we will certainly come to think about the use of it in songs. In Indonesia, Korean songs nowadays have become the most popular song among youngster music enthusiasts. Korean songs become popular along with the entrance of Korean pop culture in Indonesia. From about 10 years ago, K-pop has been well spread not only in Indonesia, but also throughout the world. Its fame has been mentioned by Kim (2016:3) "South Korea's entertainment industry has grown substantially since 1990s, producing Asia-wide and other parts of the world's successes in music".

As a result, many Korean singers recently start producing many English songs so that they can attract more music enthusiasts outside their country to listen to their music. Besides their own English songs, some Korean singers also produce the remake of the existed English songs by international singers, then they sing those songs again in a different arrangement. In some other cases, Korean singers often get a request to sing English songs written or sung by an American or 
British singers. For example, in 2013, Super Junior sang a song by Michael Bolton entitled "How Am I Supposed to Live Without You" for a music program and a concert in Korea. In another occasion in 2011, Taeyeon, one of Girl's Generation's members, sang a song by Rihanna entitled "Take a Bow" for a music program in Korea.

Soo Rim (2010) tries to investigate the effect of the native language, Korean, on English. It finds out that there are three different sound patterns, which have different phonological conditions in English and Korean, namely aspiration, nasalization, and palatalization. Besides providing the differences between English and Korean consonants, this study also provides some information about phonological rules that exist in Korean and this kind of information is very beneficial for the writer in conducting this present study. Even though both Soo Rim's observation and this present study talk about English and Korean phonology, especially the phonological rule that happen to the consonants, this present study uses songs as the object of the observation. Meanwhile, Hong's observation uses audio recording of people that speak some simple sentences.

The next study is conducted by Cho and Park (2006). They try to provide a thorough comparative analysis of Korean-English phonological structures and processes. This study concludes that with proper knowledge on the contrastive analysis of Korean-English phonological structures and processes, Korean students will acquire better speech delivery and interpretation quality into English. From this study, there are some information that is very beneficial in conducting this present study, such as the differences and similarities between English and Korean phonemic along with the errors that may be done by the Koreans when speaking English. Cho and Park's research is different from this present study because in this present study, the writer only focuses on consonants. The object of the research is also different because Cho and Park did not use songs as their object.

The studies above are relevant to the present research because both of them include the findings about the differences between
English and Korean phonology and phonetics. Moreover, the studies that are reviewed above have the same methodology as this present study, which is phonological approach. Those findings are very beneficial for the writer in conducting the present study because it presents the differences between English and Korean consonants and phonological differences. However, this present study is different from the above because none of the above uses songs as the data.

Motivated by the previous paragraphs, this article attempts at discussing what English consonants are changed in English songs produced by Korean singers and conclude what phonological patterns found in their pronunciation.

\section{Methodology}

The data used were English songs sung by Korean singers. They are "2 Different Things" by Wonder Girls, "Wedding Dress", "I'll be There" and "Make Love" by Bigbang, also "She" and "How Am I Supposed to Live Without You" by Super Junior. This study also analyzes the English songs sung by a South Korean pop rock band named $\mathrm{CN}$ Blue. The songs that are chosen from $\mathrm{CN}$ Blue's albums are "Teardrops", "Every time", "Feeling", and "I Don't Know Why". Those songs that are chosen above are all written in English.

Since this study analyzes changes in sounds and its pronunciation, phonological approach is applied as its approach. According to Carr (1993), phonology is the study of systems of sounds. It is also the study of the sound system of a particular language. This approach is chosen because the purpose of this research is to find out the phonological patterns in the sound change. Phonological approach is appropriate to be applied in this study for the reason that phonology is about the ways in which speech sounds form patterns, so it will give the theories to help in analyzing the data and giving the conclusion of the change that happens in English consonants.

In order to make the data easier to read, a code was given to the data. The encoding of the data was given based on the singers of the 
songs. Thus, the code would begin with K.S. which is the abbreviation of Korean Singer, and then it would be followed by a number that represents the name of the singer. The code for the data is elaborated below.

a. K.S.1 would be the code for Wonder Girls

b. K.S.2 would be the code for Super Junior

c. K.S.3 would be the code for Bigbang

d. K.S.4 would be the code for CN Blue

\section{Findings and Discussion}

There are seven consonants which are changed by Korean singers' pronunciation. Each consonant change is elaborated in the following parts.

\section{Substitution of [p] for [f]}

From the previous discussion, it is found that there is a change from consonant [f] into [p], and the substitution of [f] is always the consonant $[\mathrm{p}]$. Below are the features of consonant [f].

\section{[f] : [+labiodental, +fricative, -voiced] [p] : [+labial, +stop, -voiced]}

Based on the features of each sound, consonant [f] and [p] are different in the place of articulation where [f] is [+labiodental] because it is "produced by touching the bottom lip to the upper teeth" (McMahon, 2002:31) and $[\mathrm{p}]$ is [+bilabial] because it is "produced by bringing both upper and lower lips together" (McMahon, 2002:31). Based on the flow of the airstream, the origin consonant is [+fricative], while the after consonant is [+stops], and based on the vibration of the vocal cord, both the origin consonant and the after are [voiced].

The explanation above shows that Korean singers usually change the fricatives consonant [f] into stops consonant [p] in their pronunciation of English words. This change is caused by the absence of phoneme /f/ in Korean phonemic consonants, so it is replaced by nearby stops consonant /p/ (Cho, 2006:238). The occurrence of this consonant change in English songs sung by Korean singers is listed below.
K.S.1: [laif] $\rightarrow$ [laip], [left] $\rightarrow$ [lept]

K.S.2: [riflektıd] $\rightarrow$ [riplektıd]

K.S.3: [laIf] $\rightarrow$ [laip], [læf] $\rightarrow$ [læp]

K.S. 4: [If] $\rightarrow$ [Ip], [laif] $\rightarrow$ [laip]

From the data above, sounds [f] and [p] are preceded by diphthong /aI/, vowels /e/, $/ \mathrm{I} /$, and /æ/. Those consonants are in the natural class of [- consonantal]. Therefore, it can be concluded that in Korean singers' pronunciation, the consonant [f] will be changed into [p] when it is preceded by vowels. The notation for this rule is shown as below.

\section{$[f] \rightarrow[p] /[-$ consonantal $]$}

\section{Substitution of [b] for [v]}

The second consonant change that usually occurs in Korean singers' pronunciation of English words is the change from consonant [v] into consonant [b]. Below are the features of consonant [v].

\section{[v] : [+labiodental, +fricative, +voiced] [b] : [+bilabial, +stop, +voiced]}

Based on the features of each sound, in the place of articulation, consonant $[\mathrm{v}]$ and $[\mathrm{b}]$ are different because [v] is [+labiodental] for it is produced by bringing the bottom lip to the upper teeth and [b] is [+bilabial] for it is produced by bringing both lips together (McMahon, 2002:31). Based on the flow of the airstream, the origin consonant is [+fricative], while the after consonant is [+stops]. Then, based on the vibration of the vocal cord, both the origin consonant and the after are [+voiced].

The explanation above shows that Korean singers usually change the fricatives consonant $[\mathrm{v}]$ into stops consonant $[\mathrm{b}]$ in the pronunciation of English words. This change is a result of the absence of fricative [v] in Korean consonant, as can be seen in table 2 . Then, it is replaced by nearby stops [b]. "According to the lenis stop voicing rule in Korean's phonological rule, even though consonant [b] cannot be found as a phoneme, it actually exists in Korean as allophones" (Cho, 2006). Thus, it is easier for Korean singers to pronounce $[\mathrm{b}]$ instead of $[\mathrm{v}]$. The occurrence of 
this second consonant change is listed as follows.

K.S. 1: [mu:v] $\rightarrow$ [mu:b]

K.S. 2: [pv] $\rightarrow$ [pb], [bəliv] $\rightarrow$ [bəlib], [hæv]

$\rightarrow[\mathrm{h} æ \mathbf{b}],[\mathrm{l} \Lambda \mathbf{v}] \rightarrow[\mathrm{l} \Lambda \mathbf{b}]$

K.S. 3: [vv] $\rightarrow$ [vb], [bəliv] $\rightarrow$ [bəlib], [hæv]

$\rightarrow[\mathrm{hæb}],[\mathrm{l} \Lambda \mathbf{v}] \rightarrow[\mathrm{l} \Lambda \mathbf{b}]$

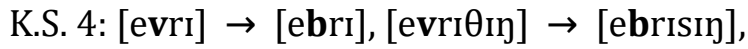
$[\mathrm{l} \Lambda \mathbf{v}] \rightarrow[1 \Lambda \mathbf{b}]$

From the data above, it is shown that that consonants $[\mathrm{v}]$ and $[\mathrm{b}]$ are preceded by vowels $/ \mathrm{u}: /, / \mathrm{p} /, / \mathrm{i} /, / \mathrm{e} /, / æ /$, and $/ \Lambda /$. Those are in the natural class [- consonantal]. Hence, for the first pattern, in Korean singers' pronunciation, consonant [v] will change into [b] when it is preceded, followed, or placed between by [consonantal]. If this rule is written in the form of a notation, it will be shown as below.

\section{$[v] \rightarrow[b] /[-$ consonantal $]$}

The next table below shows the second environment where consonant change [v] into [b] happens in Korean Singers' pronunciation.

\section{K.S. 2 : [sərvaIv] $\rightarrow$ [sərbaI]}

The datum shows that that consonants [v] and [b] are followed by the diphthong /ar/ which is in the natural class [- consonantal]. Therefore, for the first pattern, in Korean singers' pronunciation, consonant [v] will change into [b] when it is followed by [- consonantal]. In the notation, it will be shown as below.

\section{$[\mathbf{v}] \rightarrow[\mathbf{b}] / \ldots[-$ consonantal $]$}

The data below show the last environment of consonant change from the sound [v] into [b] in Korean singers' pronunciation.

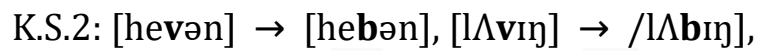
[livın] $\rightarrow$ /libın], [su:vənıər] $\rightarrow$ /su:bənıər] K.S.3: [evə(r)] $\rightarrow$ /ebə(r)], [nevə(r)] $\rightarrow$



The data show that consonants [v] and [b] placed between the vowels /u:/, /I/, /i/, /ə/, $/ \mathrm{e} /$, and $/ \Lambda /$. Those vowels are also in the natural class [- consonantal]. Thus, in Korean singers' pronunciation, consonant [v] will also be changed into [b] when it placed between by [- consonantal]. If this rule is written in the form of a notation, it will be shown as below.

$$
[v] \rightarrow[b] /[- \text { consonantal }] \_[- \text {consonantal }]
$$

\section{Substitution of [d]] for [3]}

The next consonant that is often replaced by another consonant when it is pronounced by Korean singer is consonant [3]. This consonant is usually replaced by consonant [d]. Below are the features of consonant [3].

\section{[3]: [+palato-alveolar, +fricative, +voiced] [d]]:[+palato-alveolar, -fricative, +voiced]}

From the features listed above, it can be seen that consonant [3] and [d] are both included as [+ palato-alveolar] in the place of articulation. Both consonants also share the same feature based on the vibration of the vocal cord where both are [+ voiced]. Based on the flow of the airstream, consonant [3] is [+fricative], while the after consonant is [fricative]. From the features of each consonant above, it explains that Korean singers tend to change the fricative consonant [3] into affricates consonant [d] when they sing their English songs. This change occurs since fricative [3] does not exist in Korean phonemic consonants and it is replaced by affricate [d]], which exists as the allophone of consonant $/ \mathrm{t} /$ as the result of Korean's lenis stop voicing rules. The occurrence of this consonant change is listed as follows.

\section{K.S.2: [plezər] $\rightarrow$ [pledzər], [trezər] $\rightarrow$ [tredzər], [mezər] $\rightarrow$ [medzər]}

The data above show that phoneme [3] and [d] are preceded by vowel /e/ and followed by vowel /ə/. The preceding vowel is specified as [+ front], [+ mid], and [+ tense] in natural classes. Meanwhile, the following vowel is in the natural classes of [+ central], [+ mid], and [+ reduced]. By looking at the class of those vowels, it can be concluded that consonant [3] will change into [d] when it is between [+ front] [+ mid] [+ tense] vowel and [+ central] [+ mid] [+ reduced] vowel. In the form of the rule, it will be written as below. 


\section{[3] $\rightarrow$ [d] / V [+front, +mid, +tense $] \_$V [+central, +reduced]}

\section{Substitution of [d] for [z]}

The fourth consonant that undergoes a change based on the analysis is consonant [z]. Similar to the sound [3], consonant $[\mathrm{z}]$ is also changed into consonant [d]. Below are the features of consonants [z].

\section{[z] : [+alveolar, +fricative, +voiced] \\ [d] : [+palatal, -fricative, +voiced]}

The two consonants [z] and [d] have different quality in the place of articulation where $[\mathrm{z}]$ is [+ alveolar] since this sound is "produced by raising the tip of tongue to the alveolar ridge" (McMahon, 2002:32), while [d] is [+ palatoalveolar]. In the vibration of the vocal cord, both are [+ voiced]. On the other hand, they are different in the flow of the airstream where [z] has the quality of [+ fricatives], while [d] has the quality of [- fricatives]. The occurrence of this consonant change is listed below.

\section{K.S.2: [rizən] $\rightarrow$ [ridgən]}

It is shown that there is only one example in which consonant change happens in English songs sung by Korean singer. As seen in the table, consonant $[\mathrm{z}]$ and $[\mathrm{d}]$ are preceded by vowel /i/ and followed by vowel /ə/. The preceding vowel is included in the natural class of [+ front], [+ high], and [+ tense]. Meanwhile, the following vowel is included in [+ central] [+ mid] [+ reduced]. After looking at the class of those vowels, it can be concluded that consonant [z] is changed into [d] when it comes after a [+ front] [+ high] [+ tense] vowel and before [+ central] [+ mid] [+ reduced] vowel. When the pattern in drawn in a notation, it will be written as below.

\section{[z] $\rightarrow[d]] /$ V [+front, +high, +tense $] \_$V [+central, +mid, +reduced]}

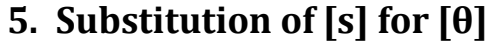

The fifth consonant that undergoes a change in English songs sung by Korean singers is consonant [ $\theta$ ]. This consonant is usually replaced by [s]. The features of sound $[\theta]$ are listed below.

\section{[0]: [+interdental, +fricative, -voiced] [s] : [+alveolar, +fricative, -voiced]}

As it is shown in the data above, those consonants have both similarity and difference in their features. They are different in the place of articulation where $[\theta]$ is [+ interdental] and $[\mathrm{s}]$ is [+ alveolar]. The sound $[\theta]$ is "produced by inserting the tip of the tongue between the upper and lower teeth, while sound [s] is produced by raising the front part of the tongue to the alveolar ridge" (McMahon, 2002:32). When it comes to the flow of the airstream, the origin and the after consonant share the same feature which is [+fricative]. Then, based on the vibration of the vocal cord, both consonants are included in [- voiced]. Those features tell that Korean singers usually replace the fricatives $[\theta]$ with fricatives $[\mathrm{s}]$ in their pronunciation.

Sound $[\theta]$ is absent in Korean phoneme while sound [s] is present there. Thus, Korean singers tend to replace $[\theta]$ with $[\mathrm{s}]$ because it is easier for them to pronounce a consonant that is present as a phoneme than the one which is not present there either as a phoneme or an allophone. The occurrence of this consonant change is shown below.

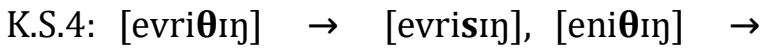

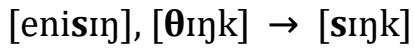

In this part, the pattern of the consonant change is very obvious. It is shown that consonant $[\theta]$ and [s] are followed by vowel /I/. This vowel has the quality of [+ front], [+ high], and [- tense]. As conclusion, in Korean singers' pronunciation, the consonant $[\theta]$ will be replaced by [s] when it comes before [+ front], [+ high], [- tense] vowel. The rule of this consonant change is drawn as below.

$$
[\theta] \rightarrow[s] / \ldots \text { V [+front, +high, -tense] }
$$

\section{Substitution of [l] for [r]}

The next is the change from consonant [l] to consonant [r]. It is found that consonant [r] is often changed or replaced by consonant [1]. In order to make the notation is easier to be 
drawn, the features of consonant [r] are listed below.

\section{[r] : [+alveolar, +approximant, -lateral] [I] : [+alveolar, +approximant, +lateral]}

The features of sounds [l] and [r] are almost the same. In the place of articulation, the origin consonant [r] and the after consonant [l] are included as [+ alveolar]. Based on the flow of the airstream, both of the consonants are [+ approximant]. However, the origin and the after sounds also have a difference. Consonant [r] is described as [lateral], while [l] is considered as [+ lateral]. This change occurs due to the fact that in Korean, "[l] and [r] are allophones of a single phoneme, with [r] produced between vowels and [1] everywhere else" (McMahon, 2002:21).

Thus, if Korean singers transfer this Korean phonological rule when they speak English, it may cause consonant change. In the table below are the occurrences of this consonant change in English songs sung by Korean singers.

K.S.2: $[\mathrm{r} \Lambda \mathrm{f}] \rightarrow[\mathrm{l} \Lambda \mathrm{f}],[$ redi $] \rightarrow[$ ledi $]$

The data show the words in which consonants [l] and $[\mathrm{r}]$ are followed by vowels $/ \Lambda /$ and $/ \mathrm{e} /$. Those vowels are in the natural class [- consonantal]. Meaning to say, in Korean singers' pronunciation, consonant [r] will change into [l] when it comes before or after [- consonantal]. In the form of notation, it is drawn as follows.

\section{$[\mathrm{r}] \rightarrow[\mathrm{l}] /[-[-$ consonantal $]$}

The next data below show the second environment where the consonant [r] will change into consonant [l] in Korean singers' pronunciation.

K.S.4: [tırdra:p] $\rightarrow$ [tıldra:p], [hir] $\rightarrow$ [hil], [tier] $\rightarrow$ [tiel], [ker] $\rightarrow$ [kel]

\section{Substitution of [J] for [s]}

The last consonant change that often occurs when Korean singers sing English songs is the change from consonant [s] into [ [] . The features of consonant [s] are listed below.

\section{[s] : [+alveolar, +fricative, -voiced] [J] : [+palato-alveolar, +fricative, -voiced]}

Based on the features above, it is found that [s] and [5] have difference in the place of articulation. Consonant [s] is included as [+ alveolar], while [J] has the quality of [+ palatealveolar]. Sound [s] is articulated by raising the tip of tongue to the alveolar ridge and [ $]$ ] is articulated by move the tongue tip to the alveolar ridge, then move to the soft palate. However, they also have similarities. The first is that both the origin and the after consonant share the same feature on the flow of the airstream which is [+ fricatives]. The other similarity lies on the vibration of the vocal cord where [s] and []] are [- voiced].

It can be concluded that alveolar fricatives [s] is often changed into []] in Korean singers' pronunciation of English words in their songs. This consonant change happens as the result of Korean palatalization process where the alveolar obstruent consonant /s / changes into its allophone []] whenever they occur before the vowel /I/ (Cho, 2006:241). The occurrence of this consonant change in English songs sung by Korean singers is shown below.

K.S.2: $[\mathbf{s i m}] \rightarrow[$ [im $]$

It is shown that consonant [s] and []] are both followed by /i/. This vowel is included in the natural class [+ high], [+ front], and [+ tense]. Thus, it can be summarized that in Korean singers' pronunciation, consonant [s] will be changed into []] when it comes before [+ high] [+ front] [+ tense] vowel. In the form of notation, this consonant change can be written as below.

\section{$[s] \rightarrow[]] / \ldots$ V [+front, +high, +tense]}

From the analysis and discussion conducted in this chapter, it is found that consonants that usually undergo a change in Korean singers' pronunciation are consonants $[\theta],[\mathrm{s}],[\mathrm{f}],[\mathrm{v}],[\mathrm{z}],[3]$ and [r] . According to McMahon (2002:29), consonants [ $\theta$ ] [s] [f] [v] [z] and [3] are included as fricatives, while [r] is a liquid. It can be concluded that Korean singers tend to change the fricatives and a retroflex liquid when they sing English songs. Thus, they should pay more attention to the 
pronunciation of fricative consonants and liquid consonant when they sing English songs so that they can produce the correct pronunciation as the target pronunciation.

\section{Conclusion}

Firstly, consonants /f/, /v/, /3/, and /z/ are changed in Korean singers' pronunciation because those fricative consonants are absent in Korean phonemic consonants. Such fricatives are replaced by the nearby stops or affricates that exist in Korean as a phoneme or an allophone such as [p] for [f], [b] for [v], [d] for [3], and [d]] for [z]. Those consonant changes have the same process which explains that in Korean singers' pronunciation, English fricatives that are absent in Korean usually will be changed into the nearby stops or affricates. In addition, it is also found that fricative [ $\theta]$, which is absent in Korean phonemic consonant, is usually replaced by the nearby fricative [s] in Korean singers' pronunciation.

Secondly, based on the findings, there are also found 2 consonant changes that occur as the result of some Korean phonological rules that are unconsciously transferred in Korean singers' pronunciation. The change from [r] into [l] occurs as there is a process in Korean that [r] will be changed into [l] whenever it is not between [- consonantal]. Meanwhile, the change from [s] into [J] happens as the result of Korean palatalization process.

In conclusion, there are 3 phonological process found in the consonant changes found in English songs by Korean singers. They are the process of changing the labiodental fricative consonants, alveolar fricative voiced consonant, dental fricative voiceless consonant and palato-alveolar fricative voiced consonant into their nearby stops or affricates, changing sound [r] into [l] when it does not come between vowels, and the last is palatalization process. However, based on the findings, it can also be seen that the process of changing English fricatives into stops or affricates becomes the process that mostly happen in the consonant changes found in this study. From 41 words, there are 31 words which have a consonant change by changing some English fricatives into nearby stops or affricates. Thus, the absence of those fricatives become the major cause of the consonant changes found in English songs sung by Korean singers.

\section{References}

Carr, Philip. Modern Linguitics: Phonology. London: The Macmillan Press Ltd, 1993.

Cho, Junmo \& Hae Kyeong Park. “A Comparative Analysis of Korean-English Phonological Structures and Processes for Pronunciation Pendadogy in Interpretation Training". Theories and Practices of Translation and Interpretation in Korea. Vol. 51. No. 2 (2006): 229. Erudite. (http://www.erudit.org/revue/meta/20 06/v/n2/013253ar.html?lang=en). September 14, 2016.

Fromkin, V. D. An Introduction to Language. Sydney: Hartcourt, 1991.

Fromkin, Victoria, Robert Rodman, and Nina Hyams. An Introduction to Language. New York: Michael Rosenberg, 2003.

Kim, Harry. Surfing the Korean Wave: How Kpop is taking over the world. The McGill Tribune. Students' Society of McGill University. February 2, 2016. (mcgilltribune.com). December 11, 2016.

Lee, H. K. Korean Phonology for the KAEPS System. n.p. June 25, 1999. (youngkorean.com). June 5, 2016.

Maxwell, J. "Designing a Qualitative Study" in Handbook of Applied Social Research Method. Eds. L. Bickman and D. J. Rog. Thousand Oaks, CA: Sage, 1997.

\footnotetext{
McMahon, April. An Introduction to English Phonology. Edinburgh: Edinburgh University Press Ltd. 2002.
} 
Myers, Jack \& Michael Simms. The Longman Dictionary of Poetic Terms. New York: Longman, 1989.

O'Grady, W. \& J. Archibald. An Introduction: Contemporary Linguistic Analysis. Toronto: Pearson Longman, 2004.

Richards, Jack. C. Error Analysis. London: Longman, 1977.

Shen, Chunxuan. "Using English Songs: an Enjoyable and Effective Approach to ELT". English Language Teaching. Vol. 2. No. 1. (2009): p. 92. (ccsenet.org/journal/index.php/elt/articl e/view/341/305). November 29, 2016.

Song, Jae Jung. The Korean Language: Structure, use and context. Madison: Taylor \& Francis e-Library, 2006. (en.bookfi.net/book/1064503). September 30, 2016.

Soo-Rim, Hong. "Effect of Korean Phonology on English when Koreans learn English." Thesis. Michigan: Michigan State University, 2010.

Strevens, Peter. Teaching English os an International Language. Oxford: Pergamon Press, 1980.

Vikner, S. Phonetics and Phonology. Geneva: University of Geneva, Dept. of English, 1986.

Wisung, Gratia M.G.S. The Phonological Study of Vowel Change in Colombian Speaker's Pronunciation as Seen in Character Gloria on "Modern Family" TV Series. Thesis. Yogyakarta: Sanata Dharma University, 2016.

Wolfram, Walt \& Robert Johnson. Phonological Analysis: Focus on American English. Washington: Prentice Hall Regents, 1982. 